\title{
Building Restoration: A GIS Task?
}

\author{
Daniela ZOCHER \\ Research Studios Austria, Studio iSPACE, Salzburg/Austria·daniela.zocher@researchstudio.at
}

This contribution was double-blind reviewed as full paper.

\begin{abstract}
This paper discusses ways in which GIS can support refurbishment planning in all planning hierarchies and therefore contribute to reach political goals concerning energy demand and efficiency. Results and findings from the European project AlpHouse serve as examples for potential approaches to the matter starting from simple web-mapping tools to customized expert tools and the development of new geographical indicators to the potential of fostering personal involvement and participation of a broader mass of people. The paper shows the importance of both, the availability of suitable data and the necessity of customized presentation and analysis functions. Additionally it gives an insight in how the voluntary geographical information movement could also contribute to this specific topic.
\end{abstract}

\section{Introduction}

Political authorities of all levels aim for the reduction of greenhouse gases and energy consumption (see for example RAT DER EUROPÄISCHEN UNION 2010; BMLFUW \& BMWFJ 2010). Especially in Europe the building stock and its energy demand have been identified as an important potential to reduce energy consumption not only through strict regulations for new buildings but also through restoration of the existing building stock. To fulfil this special task lots of different people play a role to lead the process to success; policy makers to lay the foundations for the desired development; planers, technicians and craftsmen for consulting, detailed planning and execution of retrofitting tasks; and building owners to actually invest.

All stakeholders are confronted with various decisions which they need supporting information for, an area GIS and geo data have been very successfully utilised for (as long as there was a spatial dimension which is certainly true for buildings). Although the concrete improvement of the buildings is a more technical issue, the buildings' surroundings need to be taken into consideration during the planning stage of building measures due to the big influence they may have on the building. This makes the refurbishment planning as big a GIS challenge as an engineering one.

Depending on which step of the planning process shall be supported, different data, methods and tools are suitable. Several examples of GIS support for various target groups involved in refurbishment planning were developed and demonstrated in the project AlpHouse - funded by the Alpine Space Programme of the European Union (EU) in the 
framework of the European Territorial Cooperation 2007-2013 - that will serve as basis for the further discussion.

\section{Data and Methods for Refurbishment Planning}

To develop an efficient strategy for the improvement of the building stock on the policy level, information on the buildings themselves is necessary to identify shortcomings. They indicate the biggest chance for improvement by tightening the legal specifications and offering financial aid for specified measures. This includes details on the building envelope (walls, roof, windows and basement), heating system and the total energy demand resulting from gains and losses.

For the preparation of on-site work not only the current state of the building but information on anything that might influence the building and its inhabitants must be taken into consideration This allows for consideration of a number of relevant data on natural and infrastructural conditions. Human needs together with technical and legal background information help identify a variety of geographical data which are relevant for various decisions during the refurbishment planning process. A selection of data and potential use cases can be found in Table 1 .

Table 1: Overview of geographical data and their potential use

\begin{tabular}{|c|c|}
\hline Input data & Use case \\
\hline $\begin{array}{l}\text { Solar insolation/irradiation } \\
\text { (monthly/daily/hourly radiation data, sun } \\
\text { position) } \\
\text { Shadow casting structures such as mountains, } \\
\text { vegetation, surrounding buildings (DEM, 3D } \\
\text { laserscan data) }\end{array}$ & $\begin{array}{l}\text { Daylight concepts (potential window } \\
\text { enlargements, glare shields) } \\
\text { Heating and cooling concept (passive solar } \\
\text { gains, sun blinds, solar thermal heat generation) } \\
\text { Solar power generation (photovoltaic potential) }\end{array}$ \\
\hline $\begin{array}{l}\text { Noise and smell emissions (ambient noise } \\
\text { cadastre, industrial zones, wind direction) }\end{array}$ & $\begin{array}{l}\text { Window and outer wall restoration (noise } \\
\text { shielding factor) } \\
\text { Ventilation system planning (reduction of } \\
\text { window opening, orientation of air inlet and } \\
\text { windows, filter quality) }\end{array}$ \\
\hline Water intrusion risk and other potential hazards & $\begin{array}{l}\text { Wall restoration (building materials, drainage } \\
\text { systems, sealing and waterproofing of basement) }\end{array}$ \\
\hline Townscape protection zone & $\begin{array}{l}\text { Window and outer wall restoration (allowed } \\
\text { materials and methods) } \\
\text { Solar thermal and power generation (permission } \\
\text { for installation) }\end{array}$ \\
\hline Supply infrastructure (gas, district heating) & Change of heating system (potential connection) \\
\hline
\end{tabular}

The use cases mentioned above are typical elements of refurbishment strategies. According to MiCKAITYTE et al. $(2008,58)$, they have to consider a technical, economic, architecture, social, ecological and cultural dimension in order to be sustainable. 
To actually use the mentioned data for the according use cases in most cases some preprocessing including classification, indicator derivation, distance raster creation, line of sight derivation and many other GIS methods will be necessary. The results can then be brought to the user as fully designed maps or as layers in web-mapping solutions which offer basic interaction and query functions. For more complex and customized results, web-mapping solutions, which offer flexible parameter, user input and on-the-fly calculations, are the tool of choice.

The following chapters describe indicator developments and prototype implementations from the project AlpHouse. They also provide examples on how the described data can be used for the specific task of refurbishment planning.

\section{Examples for GIS Based Refurbishment Planning Tools}

\subsection{Building stock maps - construction details for refurbishment strategies}

Regional planning is already making use of maps and GIS analyses for all sorts of infrastructure and policy decisions. Many examples describing the advantages and how-tos can be found in the literature since many years all over the globe. But to actually use GIS for a certain topic you need according data to describe and analyse. As for now the crucial point to use GIS for the development of an efficient regional refurbishment strategy is the availability of suitable data to base a decision on, the first considerations have to focus on how and where to get these data.

The regional geo databases host information on coordinates and perimeter of buildings, in some cases height, number of storeys and building age. Unfortunately information on construction details, heating system, energy demand and $\mathrm{CO}_{2}$ emissions is in most cases not connected to the buildings' datasets.

To overcome this obstacle different strategies can be chosen. A detailed field investigation is time and cost intensive and requires strong acceptance, support and participation of the general public. Therefore one possible approach is to suggest a catalogue of data on the buildings' construction which can be collected by outside inspection. This approach eliminates one of the difficulties being very much dependent on the home owners and opens the chance to get a quick rough overview on the outer shell of the buildings.

Within the chosen reference project AlpHouse this method was applied for a small area in the municipality of Kuchl leading to a number of maps on windows, roof types, sunblinds etc. In practice the method soon shows its weaknesses. As the data collection is based on visual assessment the quality of the result depends very much on the technical knowledge of the investigator and the visibility of construction details from public space.

Another strategy which avoids the necessity of new data collection is the usage of other databases not yet directly connected to the regional spatial databases. To utilize this possibility databases with relevant information for the assessment of the building stock's fabric and energetic condition need to be available. In case of the pilot region of the project in Salzburg some basic information is available from the national statistics. Additionally a database containing the energy certificates of buildings, which gained regional funding for erection or refurbishment measures exists. 
How to make use of these data, connect them with spatially located data and derive interpretable indicators from them is described in greater detail by ZOCHER, GRUBER \& PRINZ (2012). In short this method allows operating with much more accurate information than the previously described approach. The disadvantage of the use of this database is that it does not hold information on every building as it is only obligatory to enter the certificates for buildings that received funding. Nevertheless it holds a large sample to interpret the status of the building stock and gives a good picture of effects and changes triggered by current policy and funding schemes.

Figure 1 shows one of the output maps informing on the specific heating demand of refurbished buildings. It illustrates how efficient the energy for heating can be used after improvement measures. Comparing to a before refurbishment map allows drawing conclusions on efficiency of funding money to reduce energy demand and $\mathrm{CO}^{2}$ equivalents.

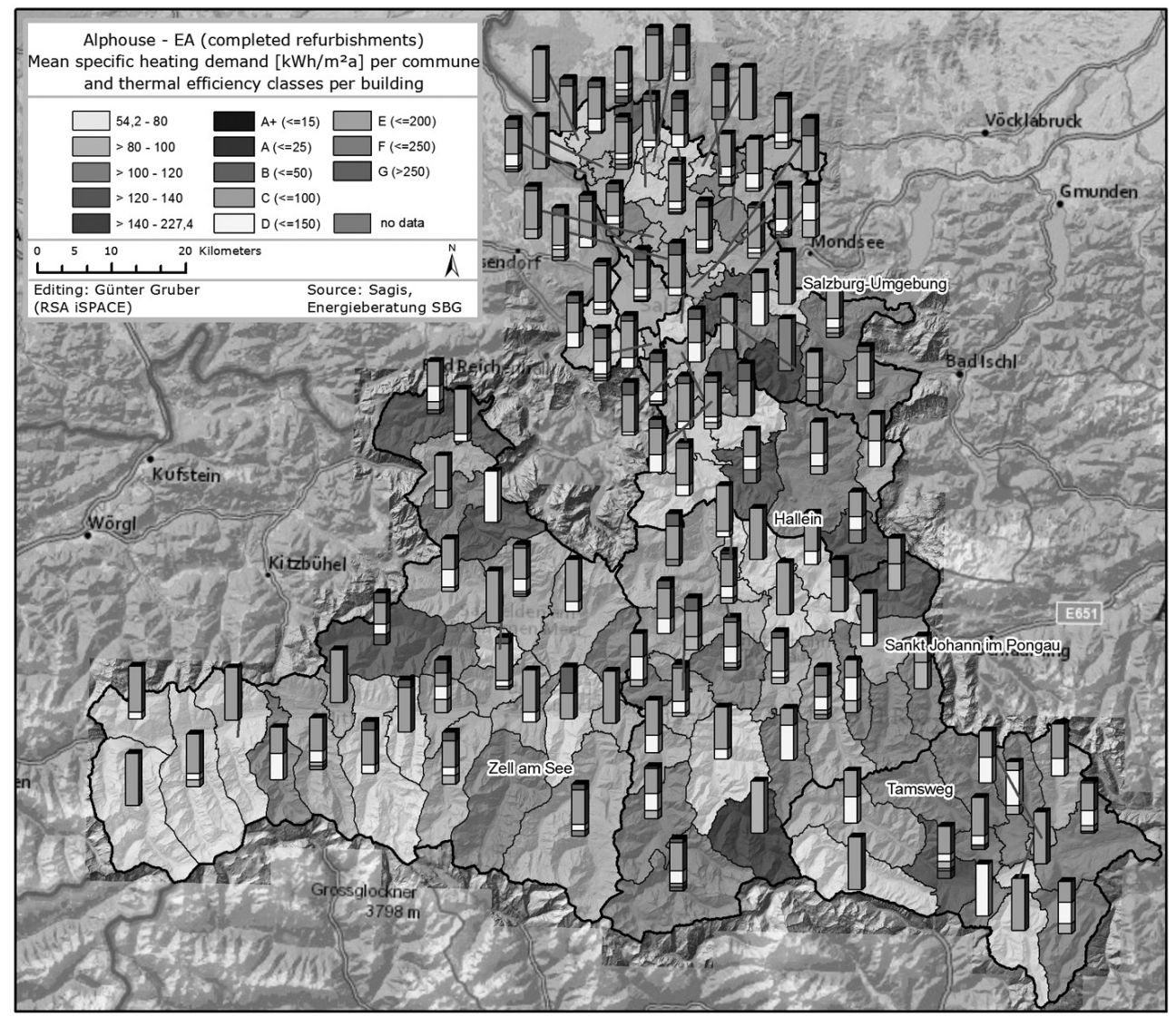

Fig. 1: Map of the heating demand of refurbished buildings with documented energy certificates (ZOCHER \& PRINZ 2012, 220) 
A third strategy, which has not been followed in detail within the mentioned project but holds a great potential, is to turn the necessity of people's involvement and contribution from a weakness into a strength by triggering a movement of voluntary geographical data collection concerning buildings' details. This strategy of using available data to show first trends in building stock development can also be used to create awareness and elicit feelings of regional pride and competition. This might not only lead to people investing more to improve their homes but could also be used to make people want to share what they have and how good their homes are. More details on how this could work will be brought up in the adjacent discussion and outlook as this has not been carried out so far.

\subsection{Simple customized web-mapping - context information for construction planning}

For the assessment of an individual building the condition of the entire building stock is of less interest. What counts for the planning of refurbishment measures is the status of the building itself and its direct surroundings as well as the needs that have to be fulfilled with the building. Therefore other data and other methods of presenting those data are necessary.

The architect, craftsman or technician in charge of the refurbishment planning is expected to recommend certain measures that are in line with regulations and produce the best result possible considering needs of inhabitants, reduction of the energy demand and the costbenefit ratio.

Data on infrastructure and local conditions which can be considered helpful in this situation are often already publicly available as geodata as they also form an important database for regional planning issues. But even if those data are not kept at the local servers of the authorities but released via web mapping services there are still obstacles for the actual use by people not used to this kind of service.

To show that these obstacles can be overcome a prototype of a customized web mapping service for refurbishment tasks was developed within the AlpHouse project. A very simplified mapping interface with basic navigation options and a simple one-click-identify function to query the information for a chosen spot was implemented for the pilot site of Hallein. The public geo databases were analysed and relevant data were selected and processed so they could easily be queried. The preparation involved mainly distance raster calculations to get continuous information from line features and classifications to ease interpretations.

As figure 2 that pictures a screenshot of the prototype shows, the query datasets are not actually visualized in the service but lie in the background of the orientation data to reduce unnecessary information overflow. The user only needs information to navigate to the object under examination. The content information itself is summarized in a compact table which should be sufficient to answer open questions on noise exposure etc. and help to calculate and choose requirements for building elements which supports the preparation for customer consultancy and the preparation for the actual construction work according to the use cases mentioned in chapter 2 . 


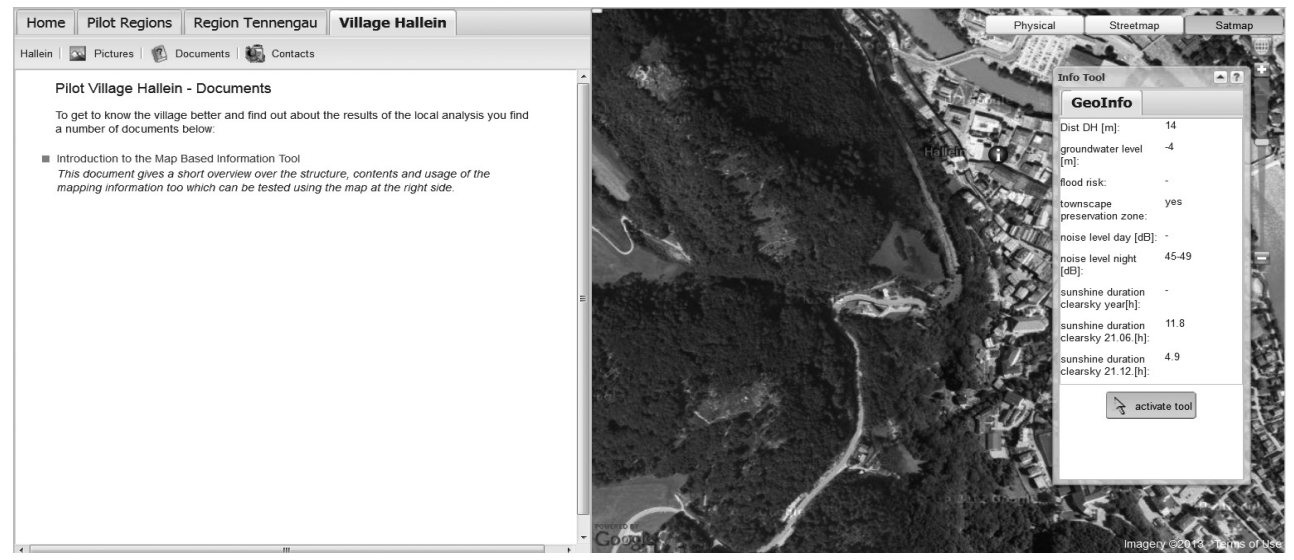

Fig. 2: Screenshot of mapping prototype for refurbishment support integrated in the information platform of the AlpHouse project website (ALPHouse 2012)

\subsection{D data and on-the-fly calculations - solar information for technical calculations}

Simple queries and the mere improvement of the access to data is not always enough. One example is the solar radiation and its various uses in the housing sector. The amount of solar radiation and the sun path at a specific geographical coordination can be derived from literature and often the information is already included in software programs the technicians use for their everyday work. Nevertheless one still needs to find out about the actual solar exposure for which the on-site shadowing situation is crucial.

Normally this involves on-site measures of the horizon around the building. To shorten this procedure and make a first assessment possible even without an on-site inspection and measurements, 3D laserscan data which are being created by more and more public institutions to amend their geographical databases can be a great help. They need however a different treatment and user interface than the simple infrastructure information mentioned before.

To actually make use of these data one needs an interface that can perform on-the-fly calculations, which do not only consider the DEM derived from the laserscan data but also some user input on the exact location, height over ground, orientation and inclination. As information on potential changes to existing roofs cannot be incorporated in pre-processed results the actual result creation cannot be resolved by a simple query.

Therefore the solution suggested within AlpHouse offers not only a selection map but also an input mask for the mentioned parameters, which are fed into the calculation implemented in the background and carried out afterwards. The outputs again are not limited to graphics and tables but also involve special files which can be directly imported in common software programs for detailed further calculations of solar energy gains, thus taking the need of otherwise necessary manual data input. 
As Fig. 3 shows the implementation creates outputs such as monthly radiation data and horizon and sun path diagrams which are common instruments and used for many calculations by this profession.

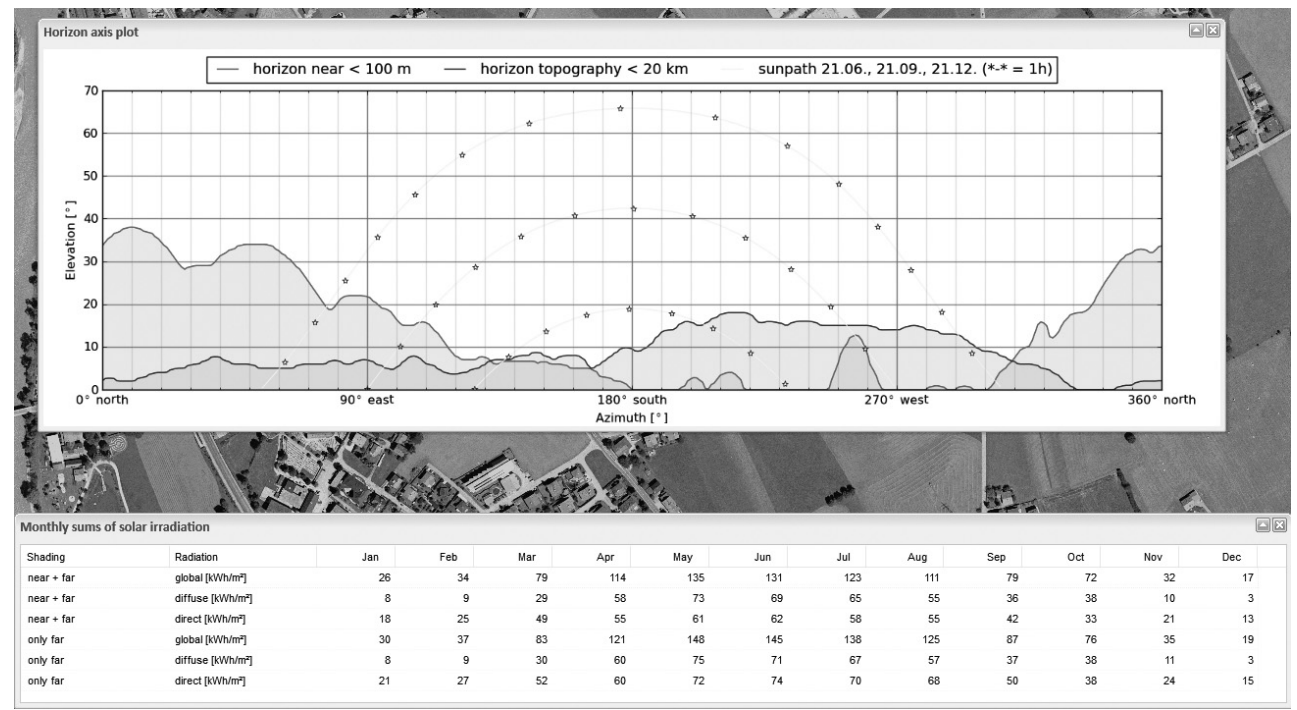

Fig. 3: Screenshot of kuchl.ubisolis.com the pilot implementation of the AlpHouse solar tool for technicians (KUCHL UBISOLIS 2012)

\section{Discussion and Conclusions}

For a long time the usage of geographical data and methods for building specific problems was very much focused on planning issues for new buildings or infrastructure around buildings. But the stronger emphasize on refurbishment tasks is only developing within the last few years when the efficiency of buildings was brought into focus by political debate.

Regional authorities and planning consultancies have licenses for GIS software packages and people trained to work with them. Sometimes they even have very specific software add-ons which may be useful for the assessment of buildings and their surroundings such as software that supports algorithms on wind and noise propagation, which also operate with spatial data, and help planners to model effects of wind flows in new building complexes or the effect of noise protection walls on settlements.

Nevertheless for smaller companies in the building sector a big specialized software product might neither be affordable nor practicable. The customer of today though expects the specialist to do some planning in advance and give advice and consultancy for their decisions especially concerning energy-efficiency and a better quality of life. This means the companies need to find a way to do that without too many expenses.

Of course these companies can make use of free services such as the web mapping portals of the regional authorities but lots of people working in the building sector might not be 
aware of such a service and its usefulness. Additionally the vast amount of data not all of them relevant or adapted and prepared for the specific task might be a big hindrance for actually making use of such a service.

The solution to make greater use of the existing public geo data also in the field of refurbishment might just be the one suggested before in chapter 3.2, filtering and preparing the data exactly for the topic "building" and the purpose of supporting general considerations and decisions to be made during the refurbishment planning process. Although the developed prototype can only be a first step towards reaching and supporting a broader mass of people and companies in the building sector - it is still lacking content and the interface needs optimization - the simplification on the one hand and the specialization on the other hand can be the crux of whether GIS can play a role in everyday refurbishment planning or not.

How the specialization can be carried a step forward without losing the advantage of the simplified web access is demonstrated by the example in 3.3. It shows that not only the access to the data themselves but the possible analyses and outputs play an important role not only to increase use and acceptance but to actually integrate the use of a Web-GIS tool into the work flow and generate interfaces to other products and procedures used by technicians, consultants and architects.

These examples show that for authorities putting some effort into shaping their databases into little online helpers can be one efficient way to push refurbishment efforts, support their small and middle sized building companies and actually help to make refurbishments a GIS task, even if most users will not be aware of the fact they are using GIS because it is one of many useful "internet tools".

As for themselves the authorities might need to make better usage of synergies than they use to. Already having software and people to work with geographical data, they need to bring together all the data collected for various purposes in different resorts to ensure multiple usages. This also guarantees for a better exploitation of according costs, a certain accurateness and up-to-dateness of the data. It opens the chance for long-term monitoring on a regular basis. As lots of data do have a geographical dimension it suggests itself to use this characteristic as a linkage between data of different origins.

The advantage resulting from this connection is that maps can even be generated to show a detailed status of the building stock as well as impacts of political measures on it. The easier interpretation and possibility to compare sub-regions within the planning area helps to make decisions and discussions more efficient, direct money where it is needed most and even make the involvement of the public more likely. The visual results created can be used as key element for participation activities which may also bring the community on board and lead to personal involvement of individuals forming the backbone of a successful refurbishment process.

The triggering of personal involvement then might be the starting point for the next step of data collection the authorities also might profit from. Since the collection and integration of data not yet recorded through an existing mechanism is quite an expensive task and often also not easily manageable due to privacy concerns, it is advisable for the authorities to take advantage of the trend of voluntary geographical data collection shown impressively by the open street map movement (http://www.openstreetmap.org/). According to HAKLAY \& 
WEBER (2008) this movement is driven by the urge to enable free access to otherwise often expensive geographical data for all sorts of daily use cases and the social aspect of sharing interests, information and spending fun time together. The latter is a driver not only for crowdsourcing projects such as Open Street Map or Wikipedia but also an important element of social platforms such as Facebook.

Coleman, Georgiadou \& Labonte (2009) summarize a whole list of motivators for people to get involved in voluntary data collection from which Altruism, Personal Interest, Social Reward and Pride of Place seem to be the most likely drivers for people to engage in collecting and publishing detailed constructional or energetic information on buildings.

Thus, if the authorities can generate a supporting environment, provide a suitable infrastructure/platform/tool and raise the interest for building specific information for example through triggering a competitive behaviour, they might profit from voluntarily shared information on buildings enhancing their knowledge on the building stock.

Inspiration on how to address and invite people to get involved and share information on an energy topic can be derived from web sites such as the "San Francisco Energy Map" (http://sfenergymap.org/) and "Solarboston" (http://gis.cityofboston.gov/solarboston/\#). While it is not the primary aim of those sites to make people enter their renewable energy installations, they give them the chance to send their data in if they cannot find their installation. By showing a huge number of existing installations, a big inducement is given to enter their data because it is a pity if nobody knows they are contributing to the greater good as well.

Using this psychological trigger combined with the findings of the before mentioned approaches a new approach fostering voluntary geographical data collection and information creation in the building sector could be created.

In general all the examples show, that geographical data, analyses and tools in their different manifestations may be one key to success in pushing building restoration forward making it a GIS task indeed.

\section{Outlook}

The question whether GIS can be relevant for refurbishment tasks is already answered, but for the future GIS can contribute even more if it evolves over time and adapts to the needs of users and the arising topics of the future also within the sustainable refurbishment process.

The trend towards a bigger customization as suggested with the development of specific prototypes focusing on the specific needs of people involved in all sorts of refurbishment planning is reflected in recent social development away from the mass product towards mass customization. (PAULI 2012) In this case this means that the trend away from the overall central web mapping service or GIS software to the small tools customized for specific topics and needs is likely to continue, maybe even go one step further offering individual personalization to create a personal toolset and forming the key to successful application in domains not yet fully covered. 
Additionally the refurbishment process can profit as well as other planning topics from the fact that people are getting more and more involved in spatial data collection (GOODCHILD 2007 ) and therefore in the future might even contribute voluntarily to collect information on the status of construction and energetic performance of buildings improving the database available for strategic decisions strengthening the use of GIS in this specific field of work.

\section{References}

AlpHouse (2012), Project website - Information platform (28.01.2013). http://www.alphouse.eu/?karte $=1$.

BMLFUW \& BMWFJ (2010), Energiestrategie Österreich, Maßnahmenvorschläge. http://www.energiestrategie.at/images/stories/pdf/longversion/energiestrategie_oesterrei ch.pdf (28.01.2013).

Coleman, D. J., Georgiadou, Y., \& Labonte, J. (2009). Volunteered geographic information: The nature and motivation of produsers. In: International Journal of Spatial Data Infrastructures Research, 4 (1), 332-358.

GoodCHILD, M. (2007), Citizens as sensors: The world of volunteered geography. Geojournal, 69, 211-221.

HAKLAY, M. \& WEBER, P. (2008), Openstreetmap: User-generated street maps. In: Pervasive Computing, IEEE, 7 (4), 12-18.

KUCHL UBISOLIS (2012), Website of solar tool prototype implementation for Kuchl within the AlpHouse project. http://kuchl.ubisolis.com/ (28.01.2013).

MiCKAITYTE, A., et al. (2008), The concept model of sustainable buildings refurbishment. International Journal of Strategic Property Management, 12/2008, 53-68.

PAULI, K. (2012), Massenware nach Maß. FAZ - Frankfurter Allgemeine Zeitung, Rubrik Wirtschaft, 24.09.2012.

http://www.faz.net/aktuell/wirtschaft/unternehmen/mass-customization-massenwarenach-mass-11900853.html (29.01.2013).

RAT DER EUROPÄISCHEN UNION (2010), Richtlinie des Europäischen Parlaments und des Rates über die Gesamtenergieeffizienz von Gebäuden - 5386/3/10 REV 3, Artikel 3. http://www.europarl.europa.eu/meetdocs/2009_2014/documents/cls/cons_cons\%282010 \%2905386\%28rev3\%29_/cons_cons\%282010\%2905386\%28rev3\%29_de.pdf (28.01.2013).

Zocher, D., Gruber, G. \& PRINZ, T. (2012), Der Einsatz von Energieausweisdaten zur Erstellung von Sanierungsindikatoren für strategische Entscheidungen und MonitoringZwecke. In: Strobl, J., BlaschKe, T., Griesebner, G. (Eds.), Angewandte Geoinformatik 2012. Berlin/Offenbach, Wichmann,569-574.

ZOCHER, D. \& PRINZ, T. (2012), Tools for decision makers and planners - How geography and technology can help us to make reasonable decisions on sustainable renovations. In: Handwerkskammer für München und Oberbayern et. al (Eds.), AlpHouse. Alpine Building Culture and Energyefficiency. Final Publication, München, 210-229 (EN/DE/ IT/FR). 